\title{
Recent advances in the diagnosis of soft tissue tumours
}

\author{
Inga-Marie Schaefer And Christopher D. M. Fletcher \\ Department of Pathology, Brigham and Women's Hospital and Harvard Medical School, \\ Boston, MA, United States
}

\begin{abstract}
Summary
Soft tissue tumours are relatively rare, but are diagnostically challenging as they comprise a large spectrum of diagnostic entities. Substantial advances have been made in recent years in identifying the underlying recurrent chromosomal and genomic alterations in a significant subset of soft tissue tumours, and this continues to enrich our understanding of the biological mechanisms of tumour development and progression. Ongoing validation and integration of these findings into existing pathological-diagnostic algorithms has led to reor subclassification of diagnostic categories and will continue to shape a more nuanced (and hopefully clinically relevant) tumour classification system in the future. This review provides a selective overview of recent diagnostic or conceptual advances in the categories of peripheral nerve sheath tumours, vascular and adipocytic tumours, round cell and myogenic sarcomas, and gastrointestinal stromal tumours, as well as their underlying molecular mechanisms, some of which have been translated successfully into useful immunohistochemical stains. A thorough and critical validation of newly identified diagnostic markers - acknowledging the fact that some genetic alterations may not necessarily be tumourspecific-and ongoing correlation with clinical and prognostic implications will be necessary in this regard.
\end{abstract}

Key words: Sarcoma; soft tissue; genomic alteration; immunohistochemical marker; classification.

Received 20 June, accepted 21 July 2017

Available online 23 September 2017

\section{INTRODUCTION}

Recent advances in the past few years have substantially changed and will continue to influence our perception of many soft tissue tumours, in particular peripheral nerve sheath tumours, epithelioid vascular and adipocytic tumours, round cell sarcomas, myogenic sarcomas, and gastrointestinal stromal tumours (GISTs). A better understanding of potential molecular drivers in these neoplasms offers the opportunity to refine current classification systems in order to take into account distinct prognostic or therapeutic implications. Loss of function of certain tumour suppressors and oncogenic fusion events are increasingly being detected, in part attributable to improved sensitivity of targeted sequencing approaches, bioinformatics algorithms for rearrangement detection, and molecular/cytogenetic analyses, along with their integration into the clinical diagnostic setting at an increasing number of institutions.
Herein we discuss newly characterised and refined diagnostic concepts or entities as part of the expanding spectrum of soft tissue tumours, driven by recurrent genomic and chromosomal alterations, and review presently available diagnostic markers. Table 1 provides an overview of the selected tumour types, associated molecular alterations, and diagnostic correlates.

\section{BIOLOGICAL SPECTRUM OF PERIPHERAL NERVE SHEATH TUMOURS}

Malignant peripheral nerve sheath tumours (MPNSTs) arise in the sporadic setting or in association with neurofibromatosis type 1 (NF1), each accounting for $\sim 50 \%$ of cases, and around $10 \%$ of cases develop post-radiation. Most MPNSTs are aggressive tumours, with 5-year survival rates of $35-50 \%$. ${ }^{1}$ Despite the presence of established diagnostic criteria for MPNSTs (which include identifiable origin from a peripheral nerve or neurofibroma, immunohistochemical/ ultrastructural evidence of Schwann cell differentiation, or a background of NF1), their diagnosis can be very challenging, especially in the absence of NF1 or an evident nerve of origin. Expression of neural markers (S100, SOX10, and GFAP) is usually limited in extent and less than $50 \%$ of MPNSTs express any of these markers, highlighting the need for more specific diagnostic tools.

In some cases, MPNST shows biological progression from conventional to atypical neurofibroma, and low grade, intermediate grade, and finally high grade MPNST, and current research endeavours aim at further clarifying the order of underlying molecular events. As an example, CDKN2A inactivation (leading to p16 loss of function) has been identified not only in MPNST, but is already present in a subset of atypical neurofibromas which credentials these tumours as precursor lesions. ${ }^{2}$ In addition, recent methylation-based studies showed that atypical neurofibromas and MPNST share overlapping methylation profiles. ${ }^{3}$ However, despite the existence of diagnostic criteria, benign and evolving malignant PNSTs occasionally represent a spectrum of disease which makes their correct diagnosis (with direct implications for clinical management) challenging in certain situations.

A recent consensus approach proposed a modified nomenclature for the spectrum of PNSTs in NF1 patients ${ }^{4}$ and identified common diagnostic challenges, such as the inconsistent distinction of atypical neurofibroma versus lowgrade MPNST for which clear diagnostic guidelines and a better understanding of the underlying genetic differences are required. However, this classification system, which is based 
Table 1 Overview of recently characterised entities and related biomarkers

\begin{tabular}{|c|c|c|c|c|c|}
\hline Tumour type & IHC & Staining pattern & $\%$ of cases & Other useful markers & Genetics \\
\hline \multicolumn{6}{|l|}{ Neural tumours } \\
\hline Epithelioid MPNST & SMARCB1 & Loss & $70 \%$ & S-100 (strong, diffuse) & \\
\hline \multicolumn{6}{|l|}{ Vascular tumours } \\
\hline $\begin{array}{l}\text { Epithelioid } \\
\text { haemangioendothelioma }\end{array}$ & CAMTA1; TFE3 & Overexpression & $90 \% ; 5 \%$ & CD31, ERG & $\begin{array}{l}\text { WWTR1-CAMTA1 fusion; } \\
\text { YAP1-TFE3 fusion }\end{array}$ \\
\hline Epithelioid haemangioma & FOSB & Overexpression & $50 \%$ & CD31, ERG & $\begin{array}{l}\text { ZFP36-FOSB fusion; } \\
\text { WWTR1-FOSB fusion; } \\
\text { FOS rearrangement }\end{array}$ \\
\hline $\begin{array}{l}\text { Pseudomyogenic } \\
\text { haemangioendothelioma }\end{array}$ & FOSB & Overexpression & $96 \%$ & CD31, ERG, keratin & SERPINE1-FOSB fusion \\
\hline \multicolumn{6}{|l|}{ Adipocytic tumours } \\
\hline $\begin{array}{l}\text { Atypical spindle cell } \\
\text { lipomatous tumour }\end{array}$ & $\mathrm{RB} 1$ & Loss & $60 \%$ & $\begin{array}{l}\text { CD34, desmin, } \\
\text { S-100 (subset) }\end{array}$ & $13 \mathrm{q} 14$ deletion \\
\hline \multicolumn{6}{|l|}{ Round cell sarcomas } \\
\hline Ewing's sarcoma & NKX2-2 & Nuclear overexpression & $>90 \%$ & $\begin{array}{l}\text { CD99 (diffuse, } \\
\text { membranous) }\end{array}$ & 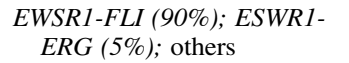 \\
\hline $\begin{array}{l}\text { Sarcoma with } C I C \\
\quad \text { rearrangement }\end{array}$ & WT1, ETV4 & Nuclear overexpression & $>90 \%$ & CD99 (limited) & $\begin{array}{l}\text { CIC-DUX4 fusion (rarely } C I C- \\
\text { FOXO4 fusion) }\end{array}$ \\
\hline $\begin{array}{l}\text { Sarcoma with } B C O R \\
\quad \text { rearrangement }\end{array}$ & BCOR & Nuclear overexpression & $>90 \%$ & CD99 (variable) & $\begin{array}{l}B C O R-C C N B 3 \text { fusion }(B C O R- \\
\quad M A M L 3 ; Z C 3 H 7 B-B C O R)\end{array}$ \\
\hline \multicolumn{6}{|l|}{ Myogenic sarcomas } \\
\hline $\begin{array}{c}\text { Spindle cell/sclerosing } \\
\text { rhabdomyosarcoma }\end{array}$ & MYOD1 & Overexpression & $100 \%$ & Desmin, myf-4 & MYOD1 mutation (p.L122R) \\
\hline \multicolumn{6}{|l|}{ GIST } \\
\hline SDH-deficient GIST & SDHB (SDHA) & Loss & $\begin{array}{l}\sim 90 \% \text { of } \\
\quad \text { KIT/PDGFRA } \\
\text { wild-type GIST }\end{array}$ & KIT, DOG1 & $\begin{array}{l}S D H A / S D H B / S D H C / S D H D \\
\text { mutation/SDHC } \\
\text { hypermethylation }\end{array}$ \\
\hline
\end{tabular}

GIST, gastrointestinal stromal tumour; IHC, immunohistochemistry; MPNST, malignant peripheral nerve sheath tumour; NF1, neurofibromatosis type 1; PRC2, polycomb repressive complex 2 ; SDH, succinate dehydrogenase complex.

on nuclear atypia, cellularity, mitotic rate, and necrosis, needs to be validated in practice. Consensus guidelines that apply to sporadic MPNSTs remain to be established.

\section{H3K27me3 loss in the differential diagnosis of MPNST}

In 2014, two groups independently identified recurrent inactivating mutations of the polycomb repressive complex 2 (PRC2) components SUZ12 or EED in $\sim 80 \%$ of MPNSTs, which result in PRC2 loss of function and thereby loss of the chromatin mark H3K27me3 (i.e., trimethylation of histone 3 at lysine 27), with subsequent oncogenic RAS pathway activation and presumed cooperation with $C D K N 2 A$ and $N F 1$ inactivation. ${ }^{5,6}$ Based on these compelling observations, our group and others have validated H3K27me3 loss as a seemingly very specific (although not fully sensitive) immunohistochemical marker for the diagnosis of MPNST. ${ }^{7-9} \mathrm{We}$ found that $\mathrm{H} 3 \mathrm{~K} 27 \mathrm{me} 3$ expression is lost in $~ 30 \%$ of low grade, $\sim 60 \%$ of intermediate grade, and $\sim 80 \%$ of high grade MPNST and that, in contrast, other spindle cell neoplasms in the differential diagnosis (including benign peripheral nerve sheath tumours) typically retain $\mathrm{H} 3 \mathrm{~K} 27 \mathrm{me} 3$ expression (Fig. 1). ${ }^{7}$

These findings suggest that PRC2 inactivation is not an initiating event in MPNST development, but likely occurs during progression from low/intermediate to higher grade tumours. Notably, almost all radiation-associated MPNSTs, but none of the epithelioid MPNSTs tested, showed loss of H3K27me3 expression. ${ }^{7,8}$ Therefore, H3K27me3 loss is a highly useful diagnostic marker with well-characterised implications for tumour biology and genomic progression in this type of sarcoma.

In a recent study, five cases of prepubertal paediatric nodular melanomas arising in congenital melanocytic naevi were reported to show markedly decreased H3K27me3 expression (i.e., loss in $50 \%$ to $>80 \%$ of tumour cells) whereas expression was retained in the adjacent naevus and normal tissue. ${ }^{10}$ In contrast, all ten adult melanomas tested in this study showed retained expression. ${ }^{10}$ PRC2 inactivating mutations have not been reported to be frequent in melanomas and the investigators hypothesise that epigenetic mechanisms may lead to H3K27me3 loss in these tumours. $^{10}$

Of note, H3K27me3 also highlights the inactivated X chromosome in female non-neoplastic (and possibly also neoplastic) cells and therefore may also aid in clarification of sample identity in the routine pathology setting (Fig. 1). ${ }^{11}$

\section{SMARCB1 loss in epithelioid schwannoma and epithelioid MPNST}

Epithelioid MPNSTs are biologically distinct from MPNST with spindled morphology and they usually do not arise in association with NF1. They exhibit distinct epithelioid cytomorphology with a strikingly lobulated growth pattern and, in contrast to conventional MPNSTs, show strong and diffuse expression of S100 protein. A significant subset of epithelioid MPNSTs $(\sim 70 \%)$ lack SMARCB1 expression. ${ }^{12}$ SMARCB1 constitutes a component of the SWI/SNF1 chromatin remodelling complex, a master regulator of 

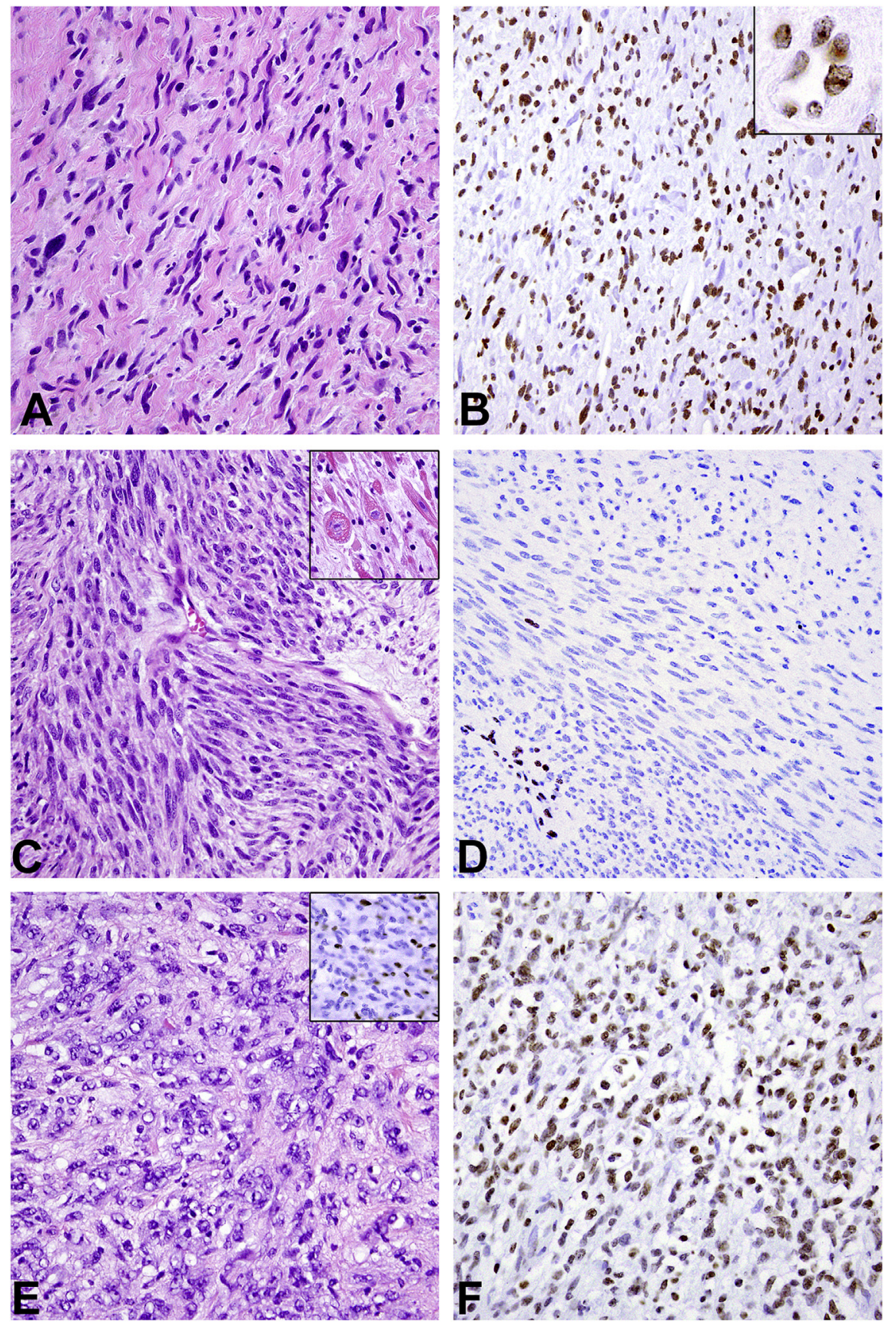

Fig. 1 (A) An atypical neurofibroma from a female patient showing (B) retained expression of H3K27me3 which also highlights the inactivated X chromosome as a single dot located at the nuclear membrane (B, inset). (C) A high grade MPNST with focal heterologous rhabdomyoblastic differentiation (C, inset) in a patient with NF1 showing (D) loss of H3K27me3 expression; vessels (bottom left) serve as positive internal control. (E) A case of epithelioid MPNST with loss of SMARCB1 in tumour cells (E, inset) exhibiting (F) retained H3K27me3 expression.

chromatin organisation and accessibility, which has been shown to harbour, in part, biological functions that oppose PRC2, again highlighting a general role of epigenetic modulators in the biology of PNSTs (Fig. 1). Similarly, epithelioid schwannomas, which may arise in schwannomatosis, have recently been described to show loss of SMARCB1 in $\sim 40 \%$ of cases. $^{13}$

\section{MOLECULAR CLASSIFICATION OF EPITHELIOID VASCULAR TUMOURS}

Significant advances have been made in the past few years, since the initial discovery of a recurrent translocation event in epithelioid haemangioendothelioma in $2001,{ }^{14}$ at the time a breakthrough in the molecular characterisation of vascular tumours. Subsequent identification of additional underlying genomic alterations in epithelioid vascular tumours - some of which have been translated into diagnostic markers-has impacted our recognition of this subgroup of tumours as being biologically diverse. Distinction of epithelioid haemangioendothelioma (which is regarded as malignant) and pseudomyogenic haemangioendothelioma (which is often multicentric and rarely metastasises), from benign lesions has implications for clinical management. These tumours and their underlying molecular alterations will be discussed here. 


\section{Epithelioid haemangioendothelioma}

Epithelioid haemangioendothelioma is considered a lowgrade malignant endothelial neoplasm with predilection for the soft tissue of extremities and trunk, often in association with a large vein, but also occurs in lung, liver, and bone, where presentation is often multifocal. Local recurrence occurs in $15 \%$, metastasis in $30 \%$ (in soft tissue sites), and the mortality ranges from $15 \%$ for soft tissue sites to $50 \%$ for tumours arising in liver and lung. Histologically, cords and strands of epithelioid endothelial cells with palely eosinophilic to glassy cytoplasm and intracytoplasmic vacuoles are characteristic, often being embedded in a myxohyaline or collagenous stroma. Epithelioid haemangioendotheliomas express CD31 and ERG and also keratins ( 25\% of cases).

The recurrent $\mathrm{t}(1 ; 3)(\mathrm{p} 36.3 ; \mathrm{q} 25)$ translocation $^{14}$ has been further characterised by two groups in 2011 and was shown to result in WWTR1-CAMTA1 gene fusion in $\sim 90 \%$ of epithelioid haemangioendotheliomas. ${ }^{15,16}$ Subsequent studies in multiple hepatic epithelioid haemangioendotheliomas further demonstrated the presence of the same WWTR1-CAMTAl fusion transcript in separate lesions in the same patient, suggesting intrahepatic metastatic disease rather than multicentric primary disease, as was previously assumed. $^{17}$ WWTR1-CAMTA1 gene fusion results in CAMTA1 overexpression (Fig. 2) and CAMTA1
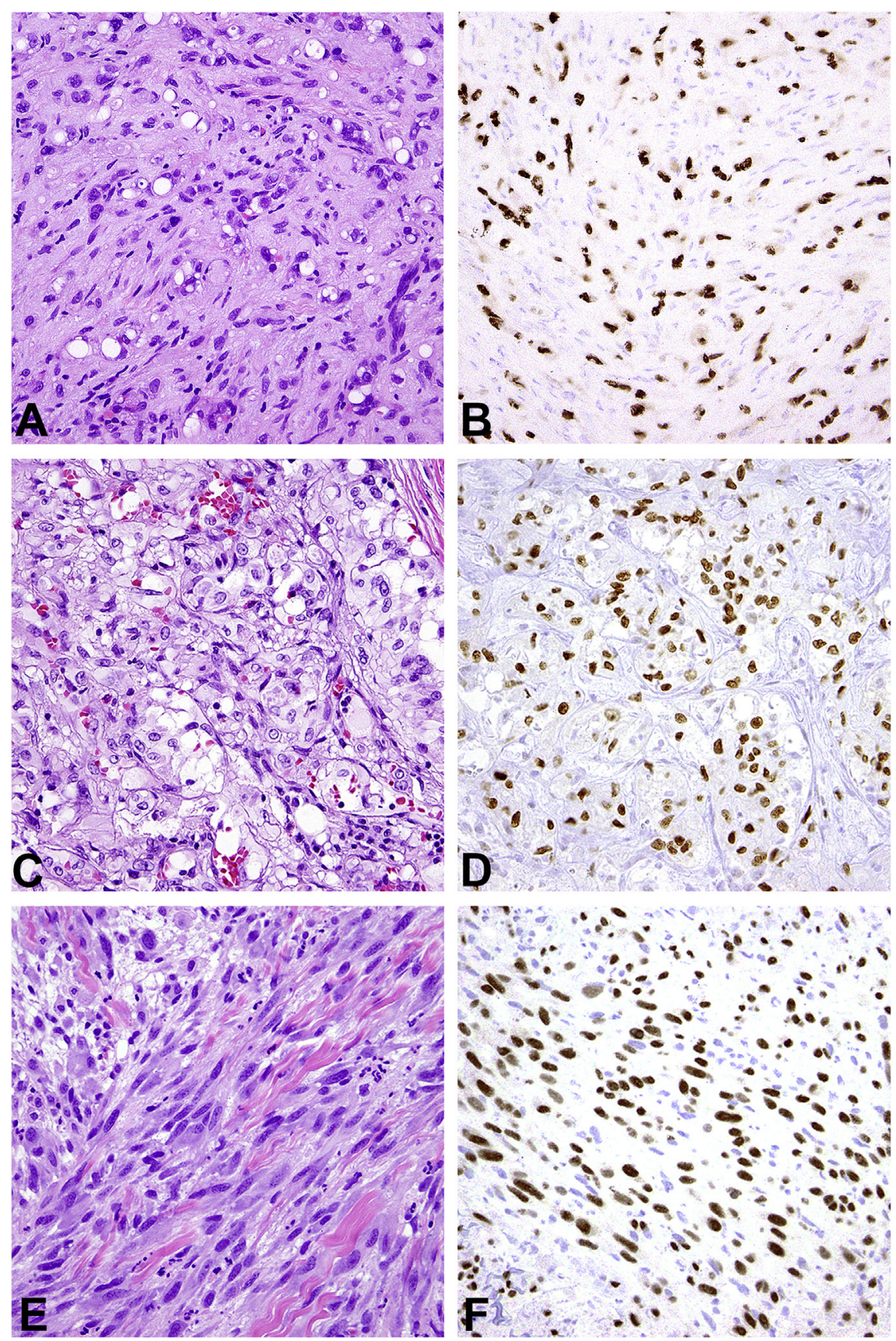

Fig. 2 (A) Epithelioid haemangioendothelioma composed of strands of epithelioid endothelial cells with characteristic vacuoles embedded in a myxohyaline stroma and (B) CAMTA1 expression suggesting the presence of WWTR1-CAMTA1 fusion; (C) another case of epithelioid haemangioendothelioma showing a more prominent vasoformative growth pattern and tumour cells with voluminous cytoplasm and TFE3 expression (D) indicating the presence of YAP1-TFE3 fusion. (E) Pseudomyogenic haemangioendothelioma displaying characteristic elongated, rhabdomyoblast-like tumour cells and (F) expression of FOSB. 
immunohistochemistry has recently been validated as a highly sensitive marker for epithelioid haemangioendothelioma in the distinction from other epithelioid vascular neoplasms. ${ }^{18}$ Approximately 5\% of cases show an alternate $\mathrm{t}(\mathrm{X} ; 11)(\mathrm{p} 11 ; \mathrm{q} 22)$ fusion event resulting in YAP1-TFE3 fusion, ${ }^{19}$ in association with distinct morphological features such as focally well-formed vascular channels and tumour cells with prominent, voluminous eosinophilic cytoplasm. This subset of epithelioid haemangioendotheliomas is negative for CAMTA1 by immunohistochemistry, but instead shows expression of TFE3 (Fig. 2) and these lesions may need to be classified separately in the future.

\section{Epithelioid haemangioma}

These benign vascular tumours commonly occur in the head and neck region, trunk, limbs, and deep soft tissue of middleaged adults, as a well circumscribed, lobular mass, often associated with a vessel. Histologically, epithelioid endothelial cells with hobnailing are found and epithelioid haemangiomas often show a characteristic zonation of well-formed vessels at the periphery and more compressed vessels in the centre of the lesion. Nuclear atypia is absent to mild, pleomorphism is usually not observed, and mitoses are not generally numerous. About $20 \%$ of cases are multifocal at presentation and, although they do not metastasise, local recurrence can occur in $\sim 30 \%$ of cases. In the past years, distinct morphological variants have been recognised. A subset of epithelioid haemangiomas which had previously been termed 'angiolymphoid hyperplasia with eosinophilia' is characterised by a predilection for the head and neck region in young adults and a prominent mixed inflammatory infiltrate consisting of lymphocytes and eosinophils. A 'cellular' subtype of epithelioid haemangiomas has recently been recognised to occur predominantly in bone and penis, with multifocality in $25 \%$ of cases and often worrisome radiological features. This subset of epithelioid haemangioma is less vasoformative and instead shows a prominently cellular or sheet-like growth pattern. Recurrent $F O S B$ gene rearrangement has been identified in $\sim 20 \%$ of cases of the 'cellular' variant, and is characterised by $\mathrm{t}(19 ; 19)(\mathrm{q} 13.2 ; \mathrm{q} 13.2)$ or interstitial del19(q13.2-3) resulting in ZFP36-FOSB gene fusion, or alternatively $\mathrm{t}(3 ; 19)(\mathrm{q} 25 ; \mathrm{q} 12)$ resulting in WWTR 1 FOSB gene fusion. ${ }^{20}$ Of note, FOSB gene rearrangements are not specific for epithelioid haemangioma and can be also be observed in pseudomyogenic haemangioendotheliomas (discussed below). In addition, $20 \%$ of cases of epithelioid haemangioma of bone and soft tissue (including the 'cellular' but also conventional subtypes) are driven by FOS gene rearrangement resulting from $t(1 ; 14)(\mathrm{q} 22 ; \mathrm{q} 24)$, $\mathrm{t}(10 ; 14)(\mathrm{p} 13 ; \mathrm{q} 24)$ or $\mathrm{t}(3 ; 14)(\mathrm{q} 25 ; \mathrm{q} 24)$, as first described in $2015 .^{21,22}$ Similar to multifocal hepatic epithelioid haemangioendotheliomas, it has been demonstrated in one patient that multifocal epithelioid haemangiomas of bone share identical fusion transcripts, confirming a presumed but unusual pattern of locoregional metastasis. ${ }^{21}$

\section{Pseudomyogenic haemangioendothelioma}

This tumour of intermediate biological potential most frequently occurs in young to middle-aged male patients and characteristically presents as multiple tumours simultaneously involving various tissue planes (such as skin, subcutis, fascia, muscle, and bone) in a given anatomical location. $^{23}$ Pseudomyogenic (also known as epithelioid sarcoma-like) haemangioendothelioma has a low potential for distant metastatic spread. Histologically, loose, infiltrative fascicles or sheets of plump spindled and epithelioid cells with prominent eosinophilic cytoplasm and frequent rhabdomyoblast-like cytomorphology are present, often accompanied by a neutrophil infiltrate. Pseudomyogenic haemangioendothelioma shows co-expression of endothelial markers, such as CD31 and ERG, and keratins, and harbours a recurrent $\mathrm{t}(7 ; 19)(\mathrm{q} 22 ; \mathrm{q} 13)$ which results in SERPINE-FOSB1 fusion. ${ }^{24}$ As demonstrated more recently, FOSB is expressed diffusely in virtually all pseudomyogenic haemangioendotheliomas and was shown to be a highly sensitive and diagnostically useful marker for pseudomyogenic haemangioendothelioma ${ }^{25}$ (Fig. 2). However, $\sim 50 \%$ of epithelioid haemangiomas (including the 'angiolymphoid hyperplasia with eosinophilia-variant'), were also found to show FOSB positivity, ${ }^{25}$ so this positivity is not specific per se.

\section{EMERGING VARIANTS OF ADIPOCYTIC TUMOURS}

Spindle cell/pleomorphic lipoma has a predilection for the shoulder, upper back, and neck region in middle-aged men. Histologically, spindle cell lipoma is composed of admixed bland spindle cells with variable amounts of mature adipocytes, and additional bizarre, hyperchromatic to multinucleate cells in pleomorphic lipoma. The tumour cells exhibit short stubby nuclei and indistinct cytoplasm, surrounded by fibromyxoid stroma with prominent 'ropey' collagen bundles, and lipoblasts may be present. Together with mammary-type myofibroblastoma and cellular angiofibroma, spindle cell/pleomorphic lipoma belongs to the family of tumours with loss of $R B 1$ caused by $13 q 14$ deletion, which translates into RB1 loss by immunohistochemistry. ${ }^{26}$

In contrast, dedifferentiated liposarcoma usually affects middle-aged to older adults, is most often located in deep soft tissue of the retroperitoneum, spermatic cord, extremities or mediastinum, spermatic cord, and head and neck region and arises in well-differentiated liposarcoma/ atypical lipomatous tumour. Pathognomonic cytogenetic alterations are giant or ring chromosomes that contain amplified material from 12q13-15 which includes the $M D M 2, C D K 4$, and HMGA2 loci. These structural abnormalities result in overexpression of MDM2 and CDK4 (and HMGA2) which is usually detectable by immunohistochemistry.

The distinction of spindle cell/pleomorphic lipoma from atypical lipomatous tumour/well-differentiated liposarcoma is usually straightforward on morphological grounds and additional fluorescence in situ hybridisation (FISH) analysis or immunohistochemical staining for MDM2, CDK4, and RB1 will help confirm these diagnoses.

\section{Atypical spindle cell lipomatous tumour}

As has been increasingly noted, a subset of atypical adipocytic neoplasms with spindle cell features does not seem to fit into any of the existing diagnostic categories. ${ }^{27-30}$ These tumours are characterised by atypical spindle cells and a variably prominent adipocytic component, associated with a 
risk of local recurrence, but lack of dedifferentiation or distant metastasis.

These low-grade tumours have been termed 'atypical spindle cell lipomatous tumours' and affect middle-aged adults with a predilection for the extremities, limb girdle, hands and feet. ${ }^{27,28,30}$ Histologically, atypical spindle cell lipomatous tumours are poorly marginated and consist of atypical spindle cells embedded in a fibrous or myxoid stroma, with a variably prominent adipocytic component showing variation in adipocyte size and focal nuclear atypia, frequently with univacuolated or multivacuolated lipoblasts (Fig. 3). ${ }^{30}$ Similar to spindle cell/pleomorphic lipoma, these tumours may show expression of CD34 and loss of RB1 (in $\sim 60 \%$ of cases, each) and lack coexpression of MDM2 and CDK4. However, $10 \%$ of cases show focal expression of either MDM2 or CDK4 by immunohistochemistry but FISH is negative for high level MDM2 amplification. In addition, staining for S100 ( 40\% of cases) and desmin ( $20 \%$ of cases) may be observed. Their mostly indolent behaviour, with local recurrence occurring in $13 \%$ of patients but no reported distant metastasis or death from disease, highlights the importance of distinguishing atypical spindle cell lipomatous tumour from atypical lipomatous tumour, in order to avoid aggressive surgical resections; most patients with atypical spindle cell lipomatous tumour will have an excellent prognosis if excision is complete.

\section{THE EXPANDING SPECTRUM OF ROUND CELL SARCOMAS}

The heterogeneous group of small round cell sarcomas, characterised by sheets of poorly differentiated cells with small, blue, round nuclei and scant cytoplasm, includes classic Ewing's sarcoma, which exhibits rearrangements involving EWSRI in the majority of cases, with EWSR I-FLI fusion resulting from $\mathrm{t}(11 ; 22)(\mathrm{q} 24 ; \mathrm{q} 12)$ being most common ( $\sim 90 \%$ of cases). In most cases, Ewing's sarcoma consists of uniform cells with rounded nuclei and inconspicuous nucleoli in diffuse sheets with variable necrosis (Fig. 4). However, various other morphological appearances have been described. ${ }^{31}$ Ewing's sarcoma typically shows strong, diffuse, membranous expression of CD99 and nuclear expression of the transcription factor NKX2-2. ${ }^{32}$

Novel emerging entities with distinct chromosomal alterations are round cell sarcomas with $C I C$ or $B C O R$ rearrangements which will be discussed in more detail.

\section{Round cell sarcoma with $C I C$ rearrangement}

In $2012,{ }^{33}$ a subset of round cell sarcomas lacking EWSRI rearrangement with predilection for the soft tissue of trunk and extremities of younger male adults were shown to harbour recurrent $C I C$ rearrangements, with $\mathrm{t}(4 ; 19)(\mathrm{q} 35 ; \mathrm{q} 13)$ or $\mathrm{t}(10 ; 19)(\mathrm{q} 26 ; \mathrm{q} 13)$ resulting most commonly in CIC-DUX4 fusion. Histologically, these tumours show primitive round to
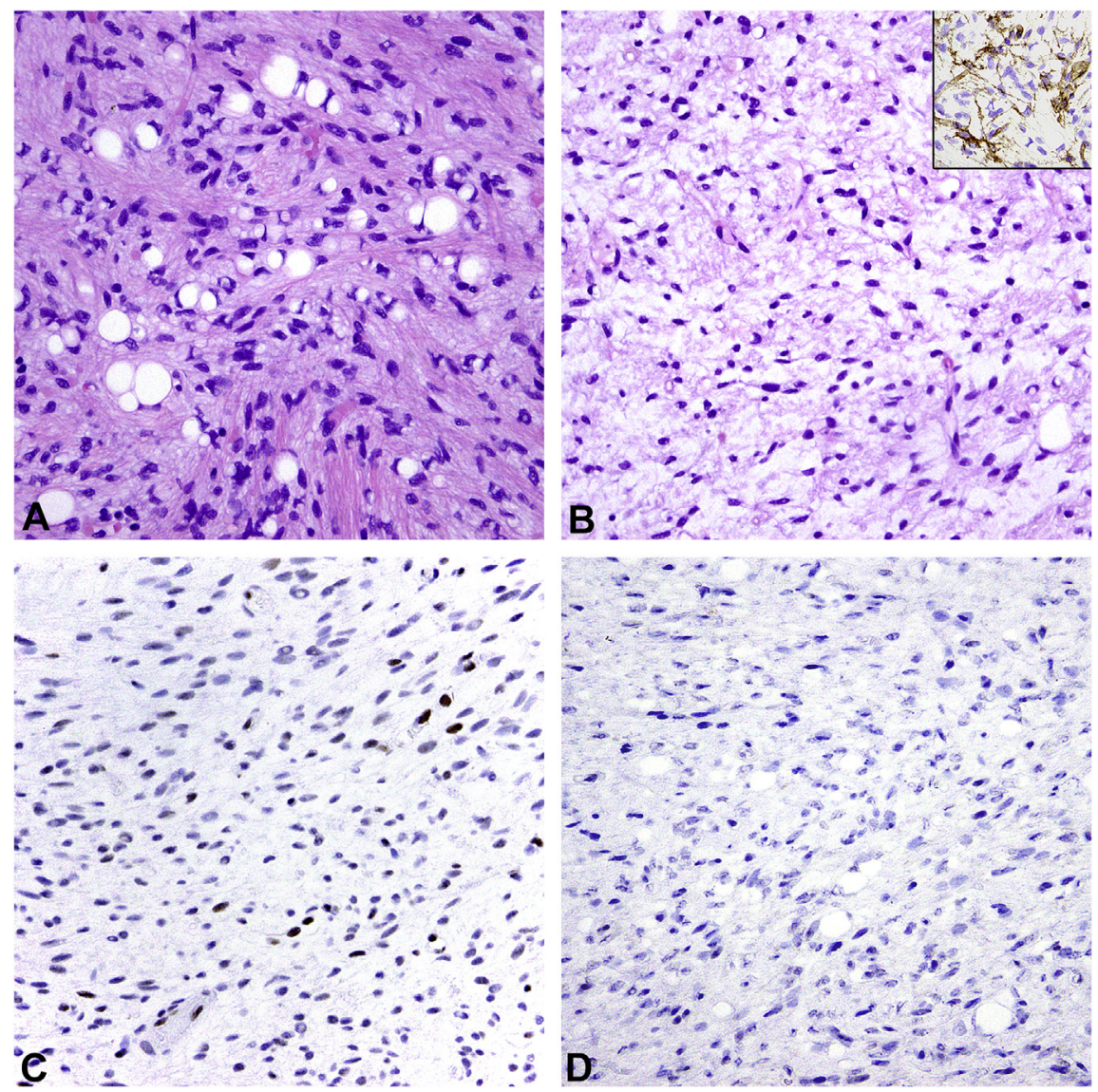

Fig. 3 (A) Atypical spindle cell lipomatous tumour showing spindled tumour cells with only mild nuclear atypia embedded in a collagenous stroma and admixed uniand multivacuolated lipoblasts. (B) Other areas showed tumour cells with short stubby nuclei embedded in a more myxoid background. (B, inset) This tumour exhibits expression of CD34 and (C) loss of RB1 in tumour cells; small vessels and inflammatory cells serve as positive internal control. (D) Staining for MDM2 is negative. 

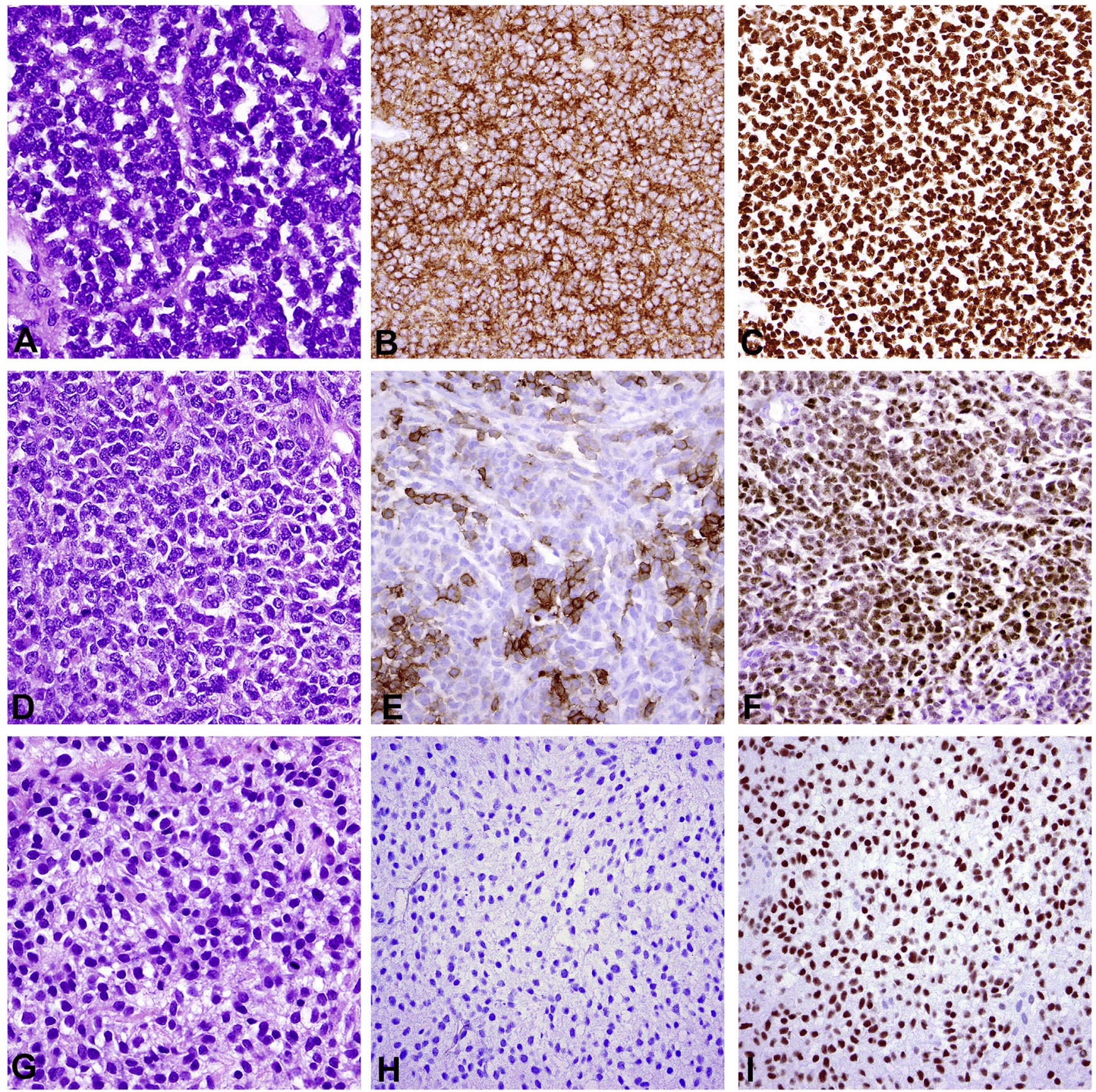

Fig. 4 (A) Ewing's sarcoma is typically comprised of a monotonous population of poorly cohesive small round cells with scant cytoplasm, shows (B) strong and diffuse membranous expression of CD99, and (C) nuclear staining for NKX2-2. (D) A case of CIC-rearranged round cell sarcoma composed of tumour cells with slightly more abundant amphophilic cytoplasm than would be expected for Ewing's sarcoma, with (E) more limited expression of CD99 in a subset of tumour cells, and (F) nuclear expression of ETV4. (G) An example of round cell sarcoma with BCOR-CCNB3 rearrangement with moderate amounts of cytoplasm lacking (H) CD99 expression with (I) diffuse nuclear reactivity for BCOR.

ovoid and sometimes spindled cytomorphology, irregularly shaped vesicular nuclei with coarse chromatin and prominent nucleoli, areas of necrosis, and frequent mitoses (Fig. 4). In contrast to Ewing's sarcoma, a higher degree of morphological heterogeneity, distinct nucleoli, more abundant (often pale) cytoplasm, and limited CD99 expression (with diffuse staining in only $\sim 20 \%$ of cases) are characteristic. In addition, it was later demonstrated that $C I C$-rearranged sarcomas show strong and diffuse nuclear staining for WT1 ( $>90 \%$ of cases) and ETV4 (90\% of cases) which aids in their distinction from
Ewing's sarcoma or BCOR-rearranged round cell sarcoma (discussed below). ${ }^{34,35}$ NKX2-2 expression has been reported in only a small subset (5\% of cases). Round cell sarcomas with CIC rearrangement behave aggressively, with lower overall survival rates compared to Ewing's sarcoma (43\% versus $76 \%) .{ }^{36}$ Although these tumours are managed clinically in a similar fashion to Ewing's sarcoma, novel treatment approaches will need to be developed as these tumours quite often develop resistance to treatment protocols established for Ewing's sarcoma. 


\section{Round cell sarcoma with $B C O R$ rearrangement}

In 2012, another subset of small round cell sarcomas lacking EWSRl or CIC rearrangement was described to harbour $B C O R-C C N B 3$ fusion resulting from $\operatorname{inv}(\mathrm{X})(\mathrm{p} 11)$ (i.e., $\mathrm{X}$ chromosomal paracentric inversion). ${ }^{37}$ This subset, which shows predilection for bone and soft tissue of male children, was further shown to have a gene expression profile distinct from other sarcomas, particularly Ewing's sarcoma. ${ }^{37}$ In addition to $C C N B 3$, the structural rearrangement may rarely involve alternate $M A M L 3$ or $Z C 3 H 7 B$ genes. ${ }^{38}$

Histologically, this subset of round cell sarcomas is characterised by monomorphic or primitive appearing round to ovoid and occasionally spindled tumour cells arranged in intersecting fascicles or a patternless fashion (Fig. 4).

Subsequently, BCOR immunohistochemistry has been validated to reliably detect protein overexpression in all cases of $B C O R$-rearranged sarcomas and also in other tumours with $B C O R$ genetic alterations (such as internal tandem duplication in primitive myxoid mesenchymal tumour of infancy). ${ }^{39,40}$ These tumours show variable expression of CD99 and lack NKX2-2, ETV4, and WT1 which helps distinguish them from Ewing's sarcoma and $C I C$-rearranged sarcoma. ${ }^{32,35}$ In addition, other tumour types such as ossifying fibromyxoid tumour and a subset of high-grade endometrial stromal sarcomas have been reported to show ZC $3 H 7 B-B C O R$ fusion. ${ }^{41,42}$

$B C O R$-rearranged sarcomas behave aggressively (although probably less aggressively than sarcomas with CIC rearrangement) with 5-year-overall survival rates of $\sim 77 \%$. ${ }^{43}$ However, the biological behaviour of these newly identified subtypes of round cell sarcoma remains to be better characterised in larger numbers of patients with longterm follow-up.

\section{MYOD1 MUTATIONS IN SPINDLE CELLI SCLEROSING RHABDOMYOSARCOMAS}

The identification of recurrent MYOD1 mutations in a subset of rhabdomyosarcomas has expanded the molecular spectrum of rhabdomyosarcoma subtypes, which includes embryonal rhabdomyosarcoma, with frequent mutations activating the RAS signalling pathway, alveolar rhabdomyosarcoma, typically containing $P A X 3-F O X O 1$ or $P A X 7-F O X O 1$ fusions, and pleomorphic rhabdomyosarcoma as the major subtypes. Spindle cell rhabdomyosarcoma (previously regarded as a variant of embryonal rhabdomyosarcoma), was initially recognised as a distinct subtype, most common in the paratesticular region in children where it is associated with a more indolent course. In adult patients, this variant has a predilection for the head and neck region and follows a more aggressive clinical course. Histologically, spindle cell rhabdomyosarcoma is characterised by two cell populations, comprising a dominant spindle cell population forming long, intersecting fascicles with ovoid to elongated nuclei and pale cytoplasm and a minor population of rhabdomyoblasts with hyperchromatic, eccentrically placed nuclei and abundant eosinophilic cytoplasm.

Sclerosing rhabdomyosarcoma has been observed as a morphological variant affecting children and adults. This variant is typically comprised of ovoid to rounded tumour cells with small amounts of cytoplasm, often arranged in nests, and embedded in a densely hyalinised stroma. However, both spindle cell and sclerosing appearances have been observed to occur in different areas of the same tumour (Fig. 5) and are nowadays considered to be two points along a histological spectrum, which were classified separately in the 2013 World Health Organization (WHO) scheme.

Similar to embryonal, alveolar, and pleomorphic rhabdomyosarcoma, spindle cell/sclerosing rhabdomyosarcoma shows expression of desmin and the myogenic transcription factors myf-4 (myogenin) and MyoD1, staining for the latter being characteristically strong and diffuse.

In 2013, a small subset of spindle cell rhabdomyosarcomas occurring in neonates and infants was reported to harbour recurrent NCOA2 gene rearrangements. ${ }^{44}$ Additional screening of rhabdomyosarcomas for recurrent genomic alterations led to the discovery of $M Y O D 1$ genomic alterations in both spindle cell and sclerosing rhabdomyosarcoma in $2014 .^{45-47}$ The activating p.L122R mutation in MYOD1, which was simultaneously reported in a significant subset of adult and paediatric spindle cell and sclerosing rhabdomyosarcomas, has been shown to result in activation of a MYClike transcriptional program and a switch from differentiation to proliferation, as histologically suggested by spindle cell morphology and a limited degree of sarcomeric differentiation. $^{45-47}$ Furthermore, MYODI mutations were found to occur in association with PIK3CA mutations and PTEN deletions, thereby altering PI3K-AKT pathway signalling. ${ }^{46,47}$

These molecular findings provide a common molecular basis and underscore that both morphological variants represent a single pathological entity, regardless of age at presentation. They help to separate spindle cell/sclerosing rhabdomyosarcoma from the embryonal, alveolar, and pleomorphic subtypes.

\section{KIT/PDGFRA WILD-TYPE GIST}

Substantial advances have been made in the past two decades, since the first clear definition as GIST in the late 1990s, at a time when this tumour was considered refractory to conventional systemic treatment options. Identification of the interstitial cells of Cajal (ICC), ${ }^{48}$ with which GISTs share expression of CD $34^{49}$ and KIT, ${ }^{50}$ as their presumed cell of origin set GISTs apart from other genetically driven soft tissue tumours in which a cell of origin or precursor lesion (such as ICC hyperplasia in GIST) can usually not be determined. Microscopic forms $(<1.0 \mathrm{~cm})$ of GIST have been shown to be surprisingly common in the general population, with these so-called 'micro GISTs' occurring in approximately $30 \%$ of individuals. ${ }^{51,52}$ Only a very small subset $(<0.1 \%)$ of these tumours progress to clinically relevant tumour with potential for metastatic spread.

Characterisation of oncogenic KIT ${ }^{33}$ and PDGFRA ${ }^{54}$ driver mutations in the majority $(\sim 85 \%)$ of GISTs paved the way for the development of targeted therapies and the successful introduction of imatinib as first line treatment for advanced/high risk GIST. Our rapidly expanding understanding of GIST biology established this tumour as the blueprint for both the identification of novel treatment targets in solid tumours and the challenge of addressing evolving treatment resistance and tumour heterogeneity. Continuous efforts are being made to overcome resistance and have led to the approval of novel tyrosine kinase inhibitors for second and third line treatment.

The first risk stratification system was established in $2002^{55}$ in order to better predict the risk of biologically 

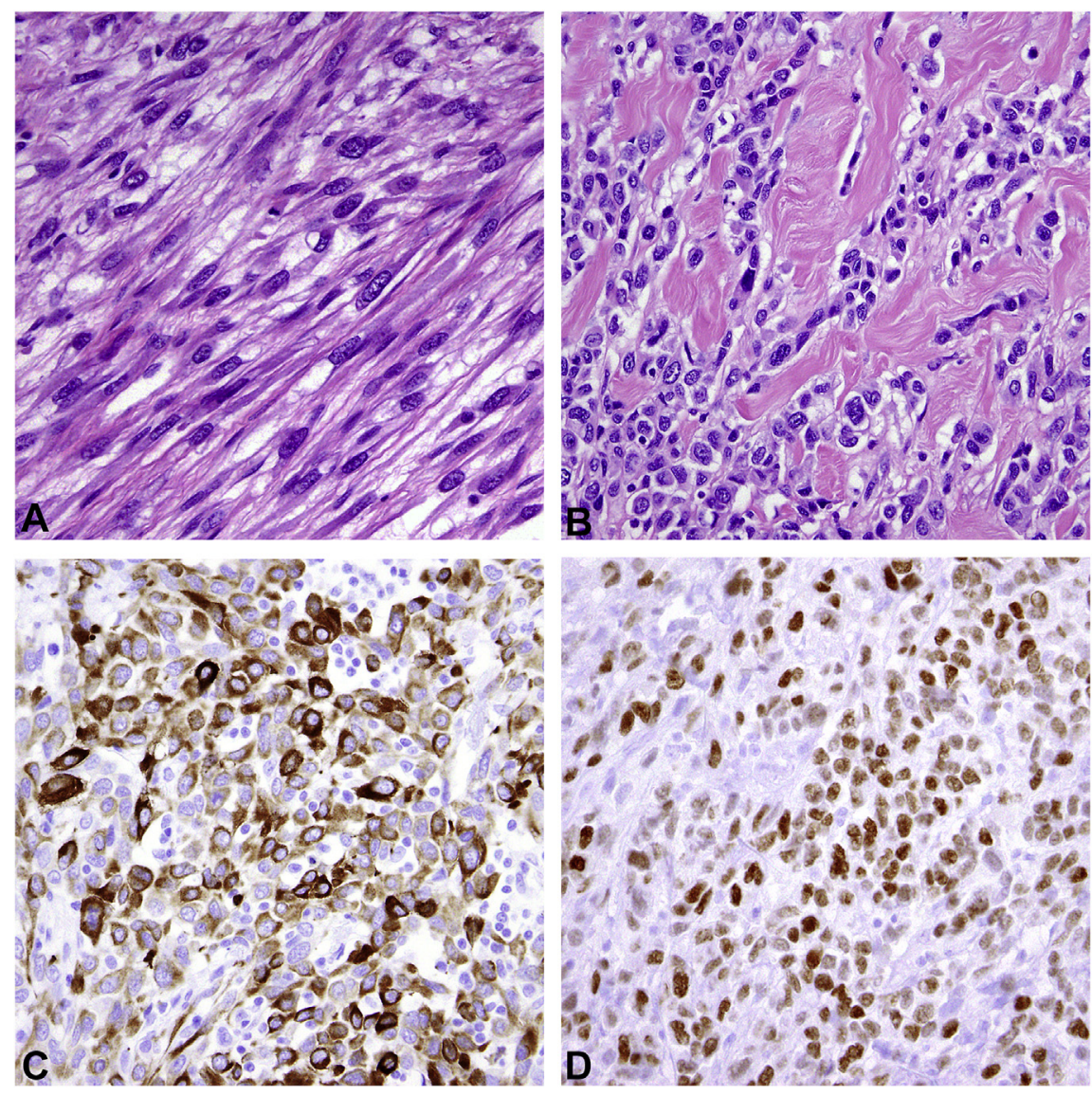

Fig. 5 A case of spindle cell/sclerosing rhabdomyosarcoma which illustrates the morphological spectrum ranging from (A) spindled tumour cells arranged in intersecting fascicles to (B) ovoid to rounded tumour cells with small amounts of cytoplasm embedded in a densely sclerotic stroma, with (C) multifocal expression of desmin and (D) diffuse nuclear staining for MYOD1.

aggressive behaviour in this multifaceted tumour with a highly variable clinical course, and the modified and improved system proposed in $2006^{56}$ (in which tumour site was added to the established parameters size and mitotic rate) has been shown to apply to the majority (i.e., 'conventional' KIT/PDGFRA-mutant GISTs).

It has been recognised that GISTs follow certain steps of genomic progression, initiated by the oncogenic tyrosine kinase mutations (which are already present in micro GISTs) and followed by chromosomal losses at 14q, 22q, 1p, and 15q which harbour putative tumour suppressor genes. Inactivation of $M A X$ (on $14 \mathrm{q})^{57}$ and dystrophin (encoded by DMD on $\mathrm{Xp})^{58}$ tumour suppressor functions have recently been identified as early and late events in GIST progression, respectively, further credentialling GIST as an evolving model of genomic progression in cancer.

The group of so-called KIT/PDGFRA wild-type GIST (accounting for $\sim 15 \%$ of cases) has attracted increasing attention over the past few years and the two major subgroups in this category, succinate dehydrogenase complex (SDH)deficient and NF1-associated GIST, will be discussed in more detail.

\section{NF1-associated GIST}

This subtype of GIST occurs in association with the NF1 tumour syndrome and is characterised by certain distinct features such as predilection for the small intestine, spindle cell morphology, and multifocality. ${ }^{59}$ NF1-associated GISTs are usually of low risk and only rarely metastasise. They harbour biallelic NF1 inactivation which supplants the lack of constitutive tyrosine kinase by downstream activation of the same signalling pathways. As recently described in a series of 22 apparently sporadic GISTs lacking mutations in KIT, $P D G F R A, S D H$ or $B R A F$, a significant number of these patients was actually found to have germ-line NF1 mutations and the authors suggest that GISTs harbouring the characteristic features described above may point to yetundiagnosed syndromic NF1. ${ }^{59}$

Despite the lack of driver KIT mutations, NF1-associated GISTs show strong expression of KIT (and also DOG1) by immunohistochemistry, but are generally resistant to TKI therapies. ${ }^{60}$ However, they share the canonical chromosomal alterations and activation of signalling pathways typical of GIST (as described above).

From a clinical standpoint, it would be important to recognise these GISTs as being NF1-associated in order to spare patients the side effects and costs of conventional TKI therapy.

\section{SDH-deficient GIST}

The largest subset of KIT/PDGFRA wild-type GISTs ( $~ 88 \%)$ is characterised by loss-of-function alterations of $\mathrm{SDH}$, an enzymatic complex involved in the citric acid cycle and electron transport chain. ${ }^{61}$ Loss of function of any of the four 

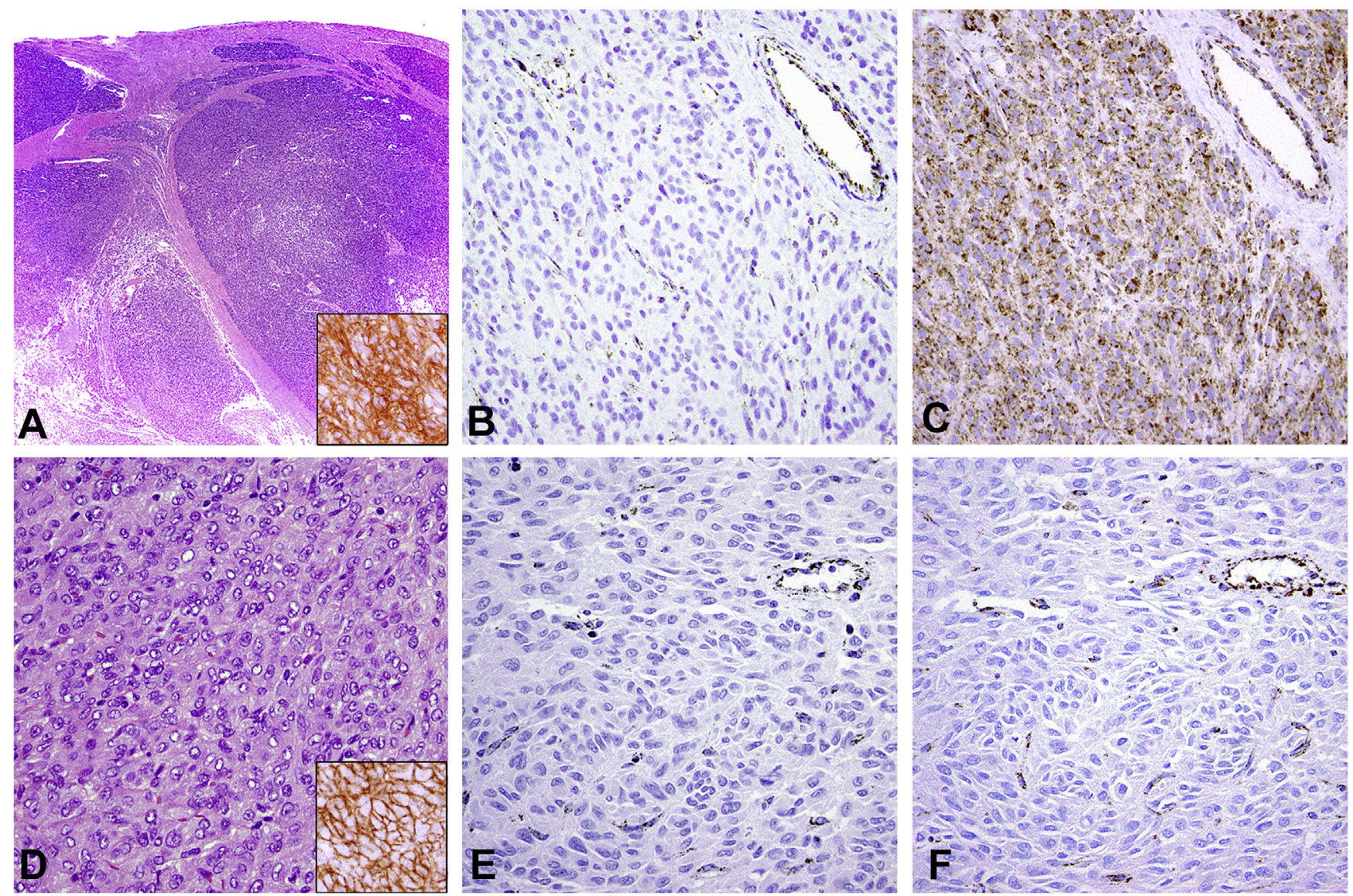

Fig. 6 (A) SDH-deficient GISTs show a characteristically multinodular growth pattern between bundles of smooth muscle which can be appreciated at low power and aids in the diagnosis. These tumours are virtually always located in the stomach, (A, inset) express DOG1 and (B) show loss of SDHB. (C) This case shows retained expression of SDHA and harboured a homozygous inactivating SDHC mutation. (D) Another SDH-deficient GIST shows characteristic epithelioid morphology with (D, inset) DOG1 expression, (E) loss of SDHB and (F) additional loss of SDHA expression, indicative of an underlying SDHA mutation; vessels (top right) serve as positive internal control.

SDH complex subunits (encoded by $S D H A, S D H B, S D H C$, and $S D H D$ ) results in loss of SDHB expression (Fig. 6). ${ }^{62}$ The majority of SDH-deficient GISTs ( $80 \%$ of cases) harbour inactivating $\mathrm{SDH}$ subunit mutations, whereas SDHC promoter methylation has been shown to account for epigenetic SDHC inactivation in the remaining $\sim 20 \%$ of cases. ${ }^{61,63}$

SDH-deficient GISTs occur in association with the nonhereditary Carney triad, ${ }^{64,65}$ together with paraganglioma and pulmonary chondroma, and in patients with the autosomal-dominant Carney-Stratakis syndrome (in association with paragangliomas) who harbour $S D H$ subunit germline mutations. ${ }^{66,67}$

The majority of GISTs in the paediatric population are wild-type for KIT and PGDFRA and most of these tumours are SDH-deficient, occurring in young patients with Carney-Stratakis syndrome or Carney triad. ${ }^{68,69}$ In general, GISTs are very rare in children and young adults, occur more often in girls, and share the histomorphological features of adult SDH-deficient GIST, with predilection for the stomach, epithelioid morphology, and multinodular growth. ${ }^{69}$

Similar to NF1-syndromic GIST, this subtype of GIST shows very distinct clinical and pathological features that set them apart from KIT/PDGFRA-mutant GISTs: SDH-deficient GISTs virtually always arise in the stomach, show epithelioid or mixed morphology, and show a typical multinodular or plexiform growth pattern within muscularis propria which facilitates their recognition at low power. ${ }^{70} \mathrm{SDH}$-deficient GISTs show expression of KIT and DOG1, but similar to NF1-associated GISTs, are generally not responsive to TKI therapy. Loss of SDHB expression confirms SDH deficiency but is non-specific in that it results from mutations in any of the four SDH subunits. Additional loss of SDHA expression indicates an underlying $S D H A$ mutation, whereas $S D H B-$, $S D H C$-, and $S D H D$-mutated/epimutated GISTs retain SDHA expression (Fig. 6). SDH-deficient GISTs lack the characteristic chromosomal alterations of conventional GIST and instead show loss at $1 \mathrm{p}$ or $1 \mathrm{q}$ (including the $S D H C$ locus). ${ }^{64,67}$

Despite a propensity for lymph node metastasis and multifocal presentation, SDH-deficient GISTs usually follow an indolent clinical course, even when metastatic. As recently demonstrated in a large series of $76 \mathrm{SDH}$-deficient GISTs, currently available risk stratification systems do not apply to this subgroup of GISTs as they fail to predict disease progression, and the identification of more specific prognostic parameters is needed. ${ }^{7}$

\section{CONCLUSION}

New insights into the molecular basis of a variety of benign and malignant soft tissue tumours have significantly advanced our understanding of this complex and genetically diverse group of tumours. Novel markers, identified through 
translational research efforts, and their incorporation in the diagnostic workup, will continue to (re-)shape the classification of soft tissue tumours in the future. Our emerging recognition of structural alterations involving recurrent translocation partners (such as EWSR1) in various unrelated neoplasms as being not tumour-specific, further strengthens the importance of a thoughtful and critical integration of molecular findings into morphological/immunohistochemical diagnostic algorithms. Based on the large number of newly described molecular drivers in the past few years, additional insights are expected to further contribute to our understanding of soft tissue tumour biology, development, and progression in the future.

Conflicts of interest and sources of funding: The authors state that there are no conflicts of interest to disclose.

Address for correspondence: Christopher D. M. Fletcher, MD, FRCPath, Department of Pathology, Brigham and Women's Hospital, 75 Francis Street, Boston, MA 02115, USA. E-mail: cfletcher@bwh.harvard.edu

\section{References}

1. Zou C, Smith KD, Liu J, et al. Clinical, pathological, and molecular variables predictive of malignant peripheral nerve sheath tumor outcome. Ann Surg 2009; 249: 1014-22.

2. Beert E, Brems H, Daniels B, et al. Atypical neurofibromas in neurofibromatosis type 1 are premalignant tumors. Genes Chromosomes Cancer 2011; 50: 1021-32.

3. Rohrich M, Koelsche C, Schrimpf D, et al. Methylation-based classification of benign and malignant peripheral nerve sheath tumors. Acta Neuropathol 2016; 131: 877-87.

4. Miettinen MM, Antonescu CR, Fletcher CDM, et al. Histopathologic evaluation of atypical neurofibromatous tumors and their transformation into malignant peripheral nerve sheath tumor in neurofibromatosis 1 patients - a consensus overview. Hum Pathol 2017; May 24; Epub ahead of print.

5. De Raedt T, Beert E, Pasmant E, et al. PRC2 loss amplifies Ras-driven transcription and confers sensitivity to BRD4-based therapies. Nature 2014; 514: 247-51.

6. Lee W, Teckie S, Wiesner T, et al. PRC2 is recurrently inactivated through EED or SUZ12 loss in malignant peripheral nerve sheath tumors. Nat Genet 2014; 46: 1227-32.

7. Schaefer IM, Fletcher CD, Hornick JL. Loss of H3K27 trimethylation distinguishes malignant peripheral nerve sheath tumors from histologic mimics. Mod Pathol 2016; 29: 4-13.

8. Prieto-Granada CN, Wiesner T, Messina JL, Jungbluth AA, Chi P, Antonescu CR. Loss of H3K27me3 expression is a highly sensitive marker for sporadic and radiation-induced MPNST. Am J Surg Pathol 2016; 40: 479-89.

9. Cleven AH, Sannaa GA, Briaire-de Bruijn I, et al. Loss of H3K27 trimethylation is a diagnostic marker for malignant peripheral nerve sheath tumors and an indicator for an inferior survival. Mod Pathol 2016; 29: 582-90.

10. Busam KJ, Shah KN, Gerami P, Sitzman T, Jungbluth AA, Kinsler V. Reduced H3K27me3 expression is common in nodular melanomas of childhood associated with congenital melanocytic nevi but not in proliferative nodules. Am J Surg Pathol 2017; 41: 396-404.

11. Schaefer IM, Minkovsky A, Hornick JL. H3K27me3 immunohistochemistry highlights the inactivated $\mathrm{X}$ chromosome (Xi) and predicts sex in non-neoplastic tissues. Histopathology 2016; 69: 702-4.

12. Jo VY, Fletcher CD. Epithelioid malignant peripheral nerve sheath tumor: clinicopathologic analysis of 63 cases. Am J Surg Pathol 2015; 39: $673-82$

13. Jo VY, Fletcher CD. SMARCB1/INI1 Loss in epithelioid schwannoma: a clinicopathologic and immunohistochemical study of 65 cases. Am J Surg Pathol 2017; 41: 1013-22.

14. Mendlick MR, Nelson M, Pickering D et al. Translocation $\mathrm{t}(1 ; 3)(\mathrm{p} 36.3 ; \mathrm{q} 25)$ is a nonrandom aberration in epithelioid hemangioendothelioma. Am J Surg Pathol 2001; 25: 684-7.

15. Errani C, Zhang L, Sung YS, et al. A novel WWTR1-CAMTA1 gene fusion is a consistent abnormality in epithelioid hemangioendothelioma of different anatomic sites. Genes Chromosomes Cancer 2011; 50: $644-53$.
16. Tanas MR, Sboner A, Oliveira AM, et al. Identification of a diseasedefining gene fusion in epithelioid hemangioendothelioma. Sci Transl Med 2011; 3: 98ra82.

17. Errani C, Sung YS, Zhang L, Healey JH, Antonescu CR. Monoclonality of multifocal epithelioid hemangioendothelioma of the liver by analysis of WWTR1-CAMTA1 breakpoints. Cancer Genet 2012; 205: 12-7.

18. Doyle LA, Fletcher CD, Hornick JL. Nuclear expression of CAMTA1 distinguishes epithelioid hemangioendothelioma from histologic mimics. Am J Surg Pathol 2016; 40: 94-102.

19. Antonescu CR, Le Loarer F, Mosquera JM, et al. Novel YAP1-TFE3 fusion defines a distinct subset of epithelioid hemangioendothelioma. Genes Chromosomes Cancer 2013; 52: 775-84.

20. Antonescu CR, Chen HW, Zhang L, et al. ZFP36-FOSB fusion defines a subset of epithelioid hemangioma with atypical features. Genes Chromosomes Cancer 2014; 53: 951-9.

21. van IDG, de Jong D, Romagosa C, et al. Fusion events lead to truncation of FOS in epithelioid hemangioma of bone. Genes Chromosomes Cancer 2015; 54: 565-74.

22. Huang SC, Zhang L, Sung YS, et al. Frequent FOS gene rearrangements in epithelioid hemangioma: a molecular study of 58 cases with morphologic reappraisal. Am J Surg Pathol 2015; 39: 1313-21.

23. Hornick JL, Fletcher CD. Pseudomyogenic hemangioendothelioma: a distinctive, often multicentric tumor with indolent behavior. Am J Surg Pathol 2011; 35: 190-201.

24. Walther C, Tayebwa J, Lilljebjorn H, et al. A novel SERPINE1-FOSB fusion gene results in transcriptional up-regulation of FOSB in pseudomyogenic haemangioendothelioma. J Pathol 2014; 232: 534-40.

25. Hung YP, Fletcher CD, Hornick JL. FOSB is a useful diagnostic marker for pseudomyogenic hemangioendothelioma. Am J Surg Pathol 2017 41: 596-606.

26. Chen BJ, Marino-Enriquez A, Fletcher CD, Hornick JL. Loss of retinoblastoma protein expression in spindle cell/pleomorphic lipomas and cytogenetically related tumors: an immunohistochemical study with diagnostic implications. Am J Surg Pathol 2012; 36: 1119-28.

27. Mentzel T, Palmedo G, Kuhnen C. Well-differentiated spindle cell liposarcoma ('atypical spindle cell lipomatous tumor') does not belong to the spectrum of atypical lipomatous tumor but has a close relationship to spindle cell lipoma: clinicopathologic, immunohistochemical, and molecular analysis of six cases. Mod Pathol 2010; 23: 729-36.

28. Creytens D, van Gorp J, Savola S, Ferdinande L, Mentzel T, Libbrecht L. Atypical spindle cell lipoma: a clinicopathologic, immunohistochemical, and molecular study emphasizing its relationship to classical spindle cell lipoma. Virchows Arch 2014; 465: 97-108.

29. Deyrup AT, Chibon F, Guillou L, Lagarde P, Coindre JM, Weiss SW. Fibrosarcoma-like lipomatous neoplasm: a reappraisal of so-called spindle cell liposarcoma defining a unique lipomatous tumor unrelated to other liposarcomas. Am J Surg Pathol 2013; 37: 1373-8.

30. Marino-Enriquez A, Nascimento AF, Ligon AH, Liang C, Fletcher CD. Atypical spindle cell lipomatous tumor: clinicopathologic characterization of 232 cases demonstrating a morphologic spectrum. Am J Surg Pathol 2017: 41: 234-44.

31. Folpe AL, Goldblum JR, Rubin BP, et al. Morphologic and immunophenotypic diversity in Ewing family tumors: a study of 66 genetically confirmed cases. Am J Surg Pathol 2005; 29: 1025-33.

32. Hung YP, Fletcher CD, Hornick JL. Evaluation of NKX2-2 expression in round cell sarcomas and other tumors with EWSR1 rearrangement: imperfect specificity for Ewing sarcoma. Mod Pathol 2016; 29: 370-80.

33. Italiano A, Sung YS, Zhang L, et al. High prevalence of CIC fusion with double-homeobox (DUX4) transcription factors in EWSR1-negative undifferentiated small blue round cell sarcomas. Genes Chromosomes Cancer 2012; 51: 207-18.

34. Specht K, Sung YS, Zhang L, Richter GH, Fletcher CD, Antonescu CR Distinct transcriptional signature and immunoprofile of CIC-DUX4 fusion-positive round cell tumors compared to EWSR1-rearranged Ewing sarcomas: further evidence toward distinct pathologic entities. Genes Chromosomes Cancer 2014; 53: 622-33.

35. Hung YP, Fletcher CD, Hornick JL. Evaluation of ETV4 and WT1 expression in CIC-rearranged sarcomas and histologic mimics. Mod Pathol 2016; 29: 1324-34.

36. Antonescu CR, Owosho AA, Zhang L, et al. Sarcomas with CICrearrangements are a distinct pathologic entity with aggressive outcome: a clinicopathologic and molecular study of 115 cases. Am J Surg Pathol 2017; 41: 941-9.

37. Pierron G, Tirode F, Lucchesi C, et al. A new subtype of bone sarcoma defined by BCOR-CCNB3 gene fusion. Nat Genet 2012; 44: 461-6.

38. Specht K, Zhang L, Sung YS, et al. Novel BCOR-MAML3 and ZC3H7B-BCOR gene fusions in undifferentiated small blue round cell sarcomas. Am J Surg Pathol 2016; 40: 433-42.

39. Kao YC, Sung YS, Zhang L, et al. BCOR overexpression is a highly sensitive marker in round cell sarcomas with BCOR genetic abnormalities. Am J Surg Pathol 2016; 40: 1670-8. 
40. Santiago T, Clay MR, Allen SJ, Orr BA. Recurrent BCOR internal tandem duplication and BCOR or BCL6 expression distinguish primitive myxoid mesenchymal tumor of infancy from congenital infantile fibrosarcoma. Mod Pathol 2017; 30: 884-91.

41. Antonescu CR, Sung YS, Chen CL, et al. Novel ZC3H7B-BCOR, MEAF6-PHF1, and EPC1-PHF1 fusions in ossifying fibromyxoid tumors-molecular characterization shows genetic overlap with endometrial stromal sarcoma. Genes Chromosomes Cancer 2014; 53 $183-93$.

42. Hoang LN, Aneja A, Conlon N, et al. Novel high-grade endometrial stromal sarcoma: a morphologic mimicker of myxoid leiomyosarcoma. Am J Surg Pathol 2017; 41: 12-24.

43. Cohen-Gogo S, Cellier C, Coindre JM, et al. Ewing-like sarcomas with BCOR-CCNB3 fusion transcript: a clinical, radiological and pathological retrospective study from the Societe Francaise des Cancers de L'Enfant. Pediatr Blood Cancer 2014; 61: 2191-8.

44. Mosquera JM, Sboner A, Zhang L, et al. Recurrent NCOA2 gene rearrangements in congenital/infantile spindle cell rhabdomyosarcoma. Genes Chromosomes Cancer 2013; 52: 538-50.

45. Szuhai K, de Jong D, Leung WY, Fletcher CD, Hogendoorn PC. Transactivating mutation of the MYOD1 gene is a frequent event in adult spindle cell rhabdomyosarcoma. J Pathol 2014; 232: 300-7.

46. Kohsaka S, Shukla N, Ameur N, et al. A recurrent neomorphic mutation in MYOD1 defines a clinically aggressive subset of embryonal rhabdomyosarcoma associated with PI3K-AKT pathway mutations. Nat Genet 2014; 46: 595-600.

47. Agaram NP, Chen CL, Zhang L, LaQuaglia MP, Wexler L, Antonescu CR. Recurrent MYOD1 mutations in pediatric and adult sclerosing and spindle cell rhabdomyosarcomas: evidence for a common pathogenesis. Genes Chromosomes Cancer 2014; 53: 779-87.

48. Perez-Atayde AR, Shamberger RC, Kozakewich HW. Neuroectodermal differentiation of the gastrointestinal tumors in the Carney triad. A ultrastructural and immunohistochemical study. Am J Surg Pathol 1993 17: 706-14.

49. Miettinen M, Virolainen M, Maarit Sarlomo R. Gastrointestinal stromal tumors-value of CD34 antigen in their identification and separation from true leiomyomas and schwannomas. Am J Surg Pathol 1995; 19: $207-16$

50. Sarlomo-Rikala M, Kovatich AJ, Barusevicius A, Miettinen M. CD117: a sensitive marker for gastrointestinal stromal tumors that is more specific than CD34. Mod Pathol 1998; 11: 728-34.

51. Agaimy A, Wunsch PH, Hofstaedter F, et al. Minute gastric sclerosing stromal tumors (GIST tumorlets) are common in adults and frequently show c-KIT mutations. Am J Surg Pathol 2007; 31: 113-20.

52. Agaimy A, Wunsch PH, Dirnhofer S, Bihl MP, Terracciano LM, Tornillo L. Microscopic gastrointestinal stromal tumors in esophagea and intestinal surgical resection specimens: a clinicopathologic, immunohistochemical, and molecular study of 19 lesions. Am J Surg Pathol 2008; 32: 867-73.

53. Hirota S, Isozaki K, Moriyama Y, et al. Gain-of-function mutations of ckit in human gastrointestinal stromal tumors. Science 1998: 279: 577-80.

54. Heinrich MC, Corless CL, Duensing A, et al. PDGFRA activating mutations in gastrointestinal stromal tumors. Science 2003; 299: $708-10$.

55. Fletcher CD, Berman JJ, Corless C, et al. Diagnosis of gastrointestinal stromal tumors: A consensus approach. Hum Pathol 2002; 33: 459-65.
56. Miettinen M, Lasota J. Gastrointestinal stromal tumors: pathology and prognosis at different sites. Semin Diagn Pathol 2006; 23: 70-83.

57. Schaefer IM, Wang Y, Liang CW, et al. MAX inactivation is an early event in GIST development that regulates p16 and cell proliferation. Nat Commun 2017; 8: 14674.

58. Wang Y, Marino-Enriquez A, Bennett RR, et al. Dystrophin is a tumor suppressor in human cancers with myogenic programs. Nat Genet 2014; 46: $601-6$.

59. Gasparotto D, Rossi S, Polano M, et al. Quadruple-negative GIST is a sentinel for unrecognized neurofibromatosis type 1 syndrome. Clin Cancer Res 2017; 23: 273-82.

60. Mussi C, Schildhaus HU, Gronchi A, Wardelmann E, Hohenberger P. Therapeutic consequences from molecular biology for gastrointestinal stromal tumor patients affected by neurofibromatosis type 1. Clin Cancer Res 2008; 14: 4550-5.

61. Boikos SA, Pappo AS, Killian JK, et al. Molecular subtypes of KIT/ PDGFRA wild-type gastrointestinal stromal tumors: a report from the National Institutes of Health Gastrointestinal Stromal Tumor Clinic JAMA Oncol 2016; 2: 922-8.

62. Janeway KA, Kim SY, Lodish M, et al. Defects in succinate dehydrogenase in gastrointestinal stromal tumors lacking KIT and PDGFRA mutations. Proc Natl Acad Sci USA 2011; 108: 314-8.

63. Haller F, Moskalev EA, Faucz FR, et al. Aberrant DNA hypermethylation of SDHC: a novel mechanism of tumor development in Carney triad. Endocr Relat Cancer 2014; 21: 567-77.

64. Matyakhina L, Bei TA, McWhinney SR, et al. Genetics of carney triad: recurrent losses at chromosome 1 but lack of germline mutations in genes associated with paragangliomas and gastrointestinal stromal tumors. J Clin Endocrinol Metab 2007; 92: 2938-43.

65. Killian JK, Miettinen M, Walker RL, et al. Recurrent epimutation of SDHC in gastrointestinal stromal tumors. Sci Transl Med 2014; 6: 268ra177.

66. Pasini B, McWhinney SR, Bei T, et al. Clinical and molecular genetics of patients with the Carney-Stratakis syndrome and germline mutation of the genes coding for the succinate dehydrogenase subunits SDHB, SDHC, and SDHD. Eur J Hum Genet 2008; 16: 79-88.

67. Stratakis CA, Carney JA. The triad of paragangliomas, gastric stromal tumours and pulmonary chondromas (Carney triad), and the dyad of paragangliomas and gastric stromal sarcomas (Carney-Stratakis syndrome): molecular genetics and clinical implications. J Intern Med 2009 266: 43-52.

68. Janeway KA, Liegl B, Harlow A, et al. Pediatric KIT wild-type and plateletderived growth factor receptor alpha-wild-type gastrointestinal stromal tumors share KIT activation but not mechanisms of genetic progression with adult gastrointestinal stromal tumors. Cancer Res 2007; 67: 9084-8.

69. Belinsky MG, Rink L, von Mehren M. Succinate dehydrogenase deficiency in pediatric and adult gastrointestinal stromal tumors. Front Oncol 2013; 3: 117

70. Doyle LA, Nelson D, Heinrich MC, Corless CL, Hornick JL. Loss of succinate dehydrogenase subunit B (SDHB) expression is limited to a distinctive subset of gastric wild-type gastrointestinal stromal tumours: a comprehensive genotype-phenotype correlation study. Histopathology 2012; 61: 801-9.

71. Mason EF, Hornick JL. Conventional risk stratification fails to predict progression of succinate dehydrogenase-deficient gastrointestinal stromal tumors: a clinicopathologic study of 76 cases. Am J Surg Pathol 2016; 40: 1616-21. 